\title{
Potencial alelopático de extratos aquosos de culturas de cobertura de solo na germinação e desenvolvimento inicial de Bidens pilosa
}

\section{Allelopathic potential of aqueous extracts of cover crops on the germination and development of Bidens pilosa}

\author{
Pedro Valério Dutra de Moraes $^{1 *}$; Dirceu Agostinetto ${ }^{2}$; Luis Eduardo Panozzo 3 ; \\ Leandro Galon ${ }^{4}$, Claudia Oliveira ${ }^{5}$, Taísa Dal Magro ${ }^{6}$
}

\begin{abstract}
Resumo
Objetivou-se com o trabalho avaliar a influência de extratos de culturas de cobertura de estação estival de inverno sobre o crescimento e desenvolvimento de Bidens pilosa (picão-preto). O delineamento experimental foi inteiramente casualizado, arranjado em esquema fatorial $4 \times 3 \times 5$, com quatro repetições. O fator A foi constituído pelas culturas de cobertura (canola, nabo-forrageiro, trevovesiculoso e azevém), o B pelas partes da planta (planta inteira, parte aérea ou sistema radicular) e o C pelas concentrações dos extratos vegetais $(0 ; 1 ; 2,5 ; 5$ e $10 \%$ peso/volume). Foram avaliados o índice de velocidade de germinação, a percentagem de germinação e comprimento e massa seca da parte aérea e radicular. Os extratos de canola seguidos dos de trevo-vesiculoso, apresentaram maior potencial alelopático. A parte aérea das culturas de cobertura foi a que apresentou a maior atividade alelopática. A atividade alelopática sobre a germinação e o desenvolvimento de picão-preto aumentou com o incremento da concentração dos extratos, das partes vegetais. O índice de velocidade de germinação foi o melhor indicador de atividade alelopática de culturas de cobertura sobre o picão-preto.
\end{abstract}

Palavras-chave: Brassica napus, Raphanus sativus, Trifolium vesiculosum, Lolium multiflorum

\begin{abstract}
The objective of the study was to evaluate the influence of cover crops extracts on growth and development of Bidens pilosa. The experimental design was completely randomized in factorial scheme $4 \times 3 \times 5$ with four replications. The factor A was composed by cover crops (Brassica napus; Raphanus sativus; Trifolium vesiculosum; Lolium multiflorum), B was parts plants (whole plant, shoot and root system) and $\mathrm{C}$ extracts concentrations $(0 ; 1,2.5,5$ and $10 \%$ weight / volume). Variables evaluated were: speed of germination; germination percentage; length and dry matter of shoot and root. Extracts of Brassica napus followed by extracts of Trifolium vesiculosum, in general, had more allelopathic potential. The shoots of the cover crops, presented in general larger allelopathic activity. Allelopathic activity on germination and development of Bidens pilosa increases with the increment of extracts concentration, of differents plants parts. The speed germination is the best indicator of allelopathic activity of cover crops on Bidens pilosa.
\end{abstract}

Key words: Brassica napus, Raphanus sativus, Trifolium vesiculosum, Lolium multiflorum

\footnotetext{
${ }^{1}$ Prof. D.Sc. do Dept ${ }^{\circ}$ de Agronomia, Universidade Estadual do Centro Oeste, UNICENTRO, Guarapuava, PR. E-mail:pvdmoraes@ gmail

${ }^{2}$ Prof. D.Sc. do Dept ${ }^{\mathrm{o}}$ de Fitossanidade, Faculdade de Agronomia Eliseu Maciel, UFPEL, Pelotas, RS. Bolsista em produtividade do CNPq. E-mail: agostinetto@ig.com.br

${ }^{3}$ Eng $^{\circ}$ Agr $^{\circ}$, Doutorando do Dept ${ }^{\circ}$ de Fitotecnia, Universidade Federal de Viçosa, UFV, Viçosa, MG. E-mail: lepanozzo@gmail.com

${ }^{4}$ Prof. D.Sc. do Dept $^{\circ}$ de Agronomia, Universidade Federal da Fronteira Sul, UFFS, Campus Erechim, RS. E-mail: leandro.galon@ uffs.edu.br

${ }^{5}$ Eng $^{\mathrm{a}}$ Agr $^{\mathrm{a}}$, Mestranda do Dept ${ }^{\mathrm{o}}$ de Fitossanidade, Faculdade de Agronomia Eliseu Maciel, UFPEL, Pelotas, RS. E-mail: oliveirac. agro@gmail.com

${ }^{6}$ Prof $^{\mathrm{a}}$. D.Sc. do Dept ${ }^{\mathrm{o}}$ de Agronomia, Universidade de Caxias do Sul, UCS. Caxias do Sul, RS. E-mail: taisadm@yahoo.com.br

* Autor para correspondência
} 


\section{Introdução}

O gênero Bidens, é dentre as plantas daninhas ocorrentes na cultura do milho, uma das mais importantes, pela grande produção de sementes aliada os mecanismos de dormência (CARMONA; BÔAS, 2001), causando perdas significativas na produtividade de grãos desta cultura.

Práticas de manejo que reduzam o efeito negativo da infestação, desta e de outras plantas daninhas, sobre a cultura são necessárias para obtenção de elevada produtividade de grãos. Neste sentido, o controle de plantas daninhas pelo uso de plantas de cobertura com potencial alelopático pode ser uma importante ferramenta a ser utilizada (REZENDE et al., 2003; SANTOS; CURY, 2011). Os efeitos alelopáticos podem ser avaliados através da extração de partes vegetais, com água e usando-se o extrato como umedificante em bioensaios na germinação de sementes (ALMEIDA, 1991). Desta forma, pode observar os efeitos sobre espécies silvestres quanto cultivadas e expressam-se por inibição, mais ou menos pronunciada, da germinação e do desenvolvimento da radícula ou da parte aérea das plântulas, sendo estes efeitos monitorados, assim como a taxa de controle (VYVYAN, 2002).

Os compostos alelopáticos podem inibir ou estimular o crescimento das espécies em função da concentração do extrato. Deste modo, é essencial identificar quais espécies, partes da planta e/ ou concentrações em que ocorre cada resposta específica e se ocorrem interações de aleloquímicos.

Com este estudo objetivou-se com o trabalho avaliar a influência de extratos de culturas de de cobertura de estação estival de inverno sobre o crescimento e desenvolvimento de Bidens pilosa.

\section{Material e Métodos}

As espécies vegetais canola (Brassica napus), nabo-forrageiro (Raphanus sativus), trevovesiculoso (Trifolium vesiculosum) e azevém (Lolium multiflorum), foram semeadas em casa de vegetação, em vasos plásticos preenchidos com solo com capacidade volumétrica de $8 \mathrm{~L}$.

Para o preparo dos extratos, o material foi coletado de plantas em estádio de florescimento. Os sistemas radicais das plantas, no momento da coleta, foram lavados, e posteriormente secos a sombra a temperatura ambiente, juntamente com a parte aérea. Quando o material apresentava-se seco, foi moído em moinho tipo martelo, em malha 0,1 a $0,5 \mathrm{~cm}$. Após, foi determinado o teor de umidade residual nos tecidos pela secagem de amostras em estufa à $60^{\circ} \mathrm{C}$, por período de 120 horas, para se proceder a correção da umidade, tendo como base a matéria seca.

Os extratos foram preparados na concentração de $10 \%$ peso/volume, com base no teor de matéria seca, sendo os tecidos deixados imerso em água destilada, em potes plásticos fechados por período de $24 \mathrm{~h}$ e em temperatura ambiente. Após, o extrato bruto foi filtrado em papel filtro e posteriormente em filtro a vácuo, para em seguida ser diluído em água destilada, conforme os tratamentos.

$\mathrm{O}$ experimento foi instalado em câmara de crescimento (BOD) com fotoperíodo de 12/12 h luz/escuro e temperatura constante de $25 \pm 1^{\circ} \mathrm{C}$. A germinação das sementes de Bidens pilosa (picãopreto) foi realizada em caixas gerbox (unidade experimental) sobre duas folhas de papel de germinação. Em cada gerbox, foram dispostas 36 sementes e adicionados $15 \mathrm{~mL}$ dos extratos ou água destilada, conforme os tratamentos.

O delineamento experimental utilizado foi completamente casualizado, arranjado em esquema fatorial 4 × $3 \times 5$, com quatro repetições. $\mathrm{O}$ fator $\mathrm{A}$ foi composto pelas culturas de coberturas (canola, nabo-forrageiro, trevo-vesiculoso e azevém); o B pelas partes da planta (planta inteira, parte aérea ou sistema radicular); e o $\mathrm{C}$ pelas concentrações $(0 ; 1$; 2,$5 ; 5$ e $10 \%$ peso/volume) dos extratos vegetais.

Diariamente, durante sete dias, foi realizada contagem do número de sementes germinadas, para estabelecer o índice de velocidade de germinação 
(IVG), calculado pela fórmula descrita por Maguire (1962) e modificada por Wardle, Ahmed e Nicholson (1991): $\quad \mathrm{IVG}=[\mathrm{N} 1 / 1+\mathrm{N} 2 / 2+\mathrm{N} 3 / 3+\ldots . . \mathrm{Nn} / \mathrm{n})]$, onde: N1, N2, N3 e Nn são o número de sementes germinadas; e, 1, 2, 3 e n são o número de dias após semeadura. Considerou-se como germinada a semente que apresentou radícula com a metade de seu comprimento total.

Ao final do período (sete dias), foram avaliadas: a germinação; o comprimento da parte aérea (CPA) e radicular (CR), pela medida de 15 plântulas por unidade experimental; e, massa seca da parte aérea (MSPA) e do sistema radicular (MSR), após secagem em estufa com circulação forçada de ar a temperatura de $60 \pm 5^{\circ} \mathrm{C}$.

Os valores de germinação, após avaliação de homocedasticidade, foram transformados por arco seno $\sqrt{ } \mathrm{x} / 100$. Os dados obtidos foram submetidos à análise de variância pelo teste $\mathrm{F}$ e, em caso de se constatar significância estatística, foi procedida comparação entre médias, para o fator culturas de cobertura ou partes de plantas, utilizando-se o teste de Tukey $(p \leq 0,05)$ e para o fator concentração dos extratos utilizou-se análise de regressão, utilizandose modelo não linear $(\mathrm{p} \leq 0,05), \mathrm{Y}=\mathrm{a} \mathrm{e}^{\mathrm{bx}}$, onde: $\mathrm{a}=$ valor máximo e/ou mínimo estimado para a variável resposta ou parâmetro estimado pelo modelo; $b=$ inclinação da curva; $x=$ concentração de extratos das culturas; e, e = constante.

\section{Resultados e Discussão}

Os fatores culturas de cobertura, partes da planta e concentração dos extratos apresentaram interação para a variável índice de velocidade de germinação (IVG) de picão-preto (Tabela 1). O IVG de picãopreto foi reduzido pelos extratos da planta inteira de canola nas concentrações de 5 e $10 \%$ peso/ volume) dos extratos vegetais, sendo que a maior concentração, não diferiu do extrato de trevovesiculoso (Tabela 1). Resultado semelhante foi verificado por Rizzardi et al. (2008), onde extratos de canola aplicados em aquênios de picão-preto, reduziram o IVG desta planta daninha. Isso ocorre, segundo Norsworthy (2003), devido a produção de glucosinolatos, aleloquímicos que podem ser os responsáveis pelos efeitos inibitórios no crescimento de plantas.

$\mathrm{Na}$ média dos extratos da parte aérea para cada cultura de cobertura observou-se que o nabo-forrageiro reduziu em $68 \%$ o IVG, o trevovesiculoso $67 \%$ e a canola e o azevém com $65 \%$, quando comparados às respectivas testemunhas (Tabela 1). Quando levado em consideração as duas maiores concentrações dos extratos, a canola, o trevo-vesiculoso e o azevém apresentaram comportamento semelhante para a variável redução do IVG do picão preto, sendo que o nabo-forrageiro foi diferente na inibição aos demais. Os extratos do sistema radical de nabo-forrageiro apresentaram as maiores reduções do IVG do picão-preto em relação aos aos extratos das demais culturas de cobertura de solo (Tabela 1).

Diferentes partes vegetais podem apresentar variações no potencial alelopático (KHANH et al., 2005). Neste estudo verificou-se diferenças alelopáticas entre as partes vegetais das plantas de cobertura estudadas, na redução do IVG. Os melhores resultados obtidos para as culturas canola, nabo-forrageiro, trevo-vesiculoso e azevém nas concentrações de $0 ; 1 ; 2,5 ; 5$ e $10 \%$ peso/volume dos extratos vegetais, em geral, foram nos extratos da parte aérea, diferindo de extratos da planta inteira e do sistema radical (Tabela 1).

O menor potencial alelopático dos extratos do sistema radical pode ter sido ocasionado pela lavagem usada na metodologia para retirada do solo, o que pode ter extraído as possíveis substâncias alelopáticas presentes na superficie das estruturas. Mesma semelhante foi relatada por Oliveira, Carvalho e Moraes (2002) e Severino e Christofoleti (2001). Porém, estudos com Lolium rigidum confirmam que extratos do sistema radical desta planta não exibem efeito alelopático sobre o IVG de azevém (L.multiflorum), Dactylis glomerata ou alfafa (Medicago sativa) (EMETERIO; ARROYO; CANALS, 2004). 


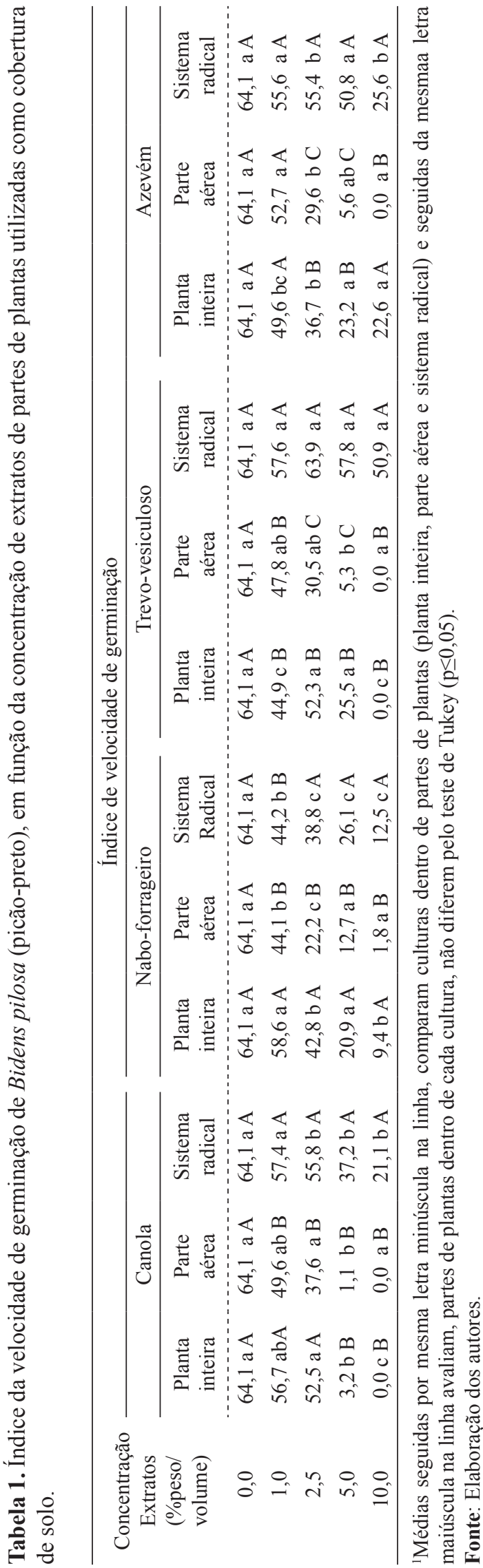

O fator concentração dos extratos das partes das culturas de cobertura, para a variável resposta IVG, demonstrou bom ajuste dos dados ao modelo observando-se o $\mathrm{R}^{2}$ com exceção do sistema radical de trevo-vesiculoso, os quais não se ajustaram ao modelo (Figura 1). Verificou-se que a parte aérea de todas as culturas de cobertura apresentou maior redução no IVG. Já, quando realizada a comparação entre culturas de coberturas dentro de partes vegetais, pode-se observar, pelo parâmetro b do modelo, que nabo-forrageiro apresentou maior redução no IVG para a parte aérea e sistema radical, contudo para a planta inteira, canola foi que proporcionou maior redução do IVG.

Os extratos das culturas de cobertura de solo apresentaram redução do IVG de modo inversamente proporcional a concentração dos extratos (Figura 1). Resultados semelhantes foram observados para trevo-persa (Trifolium resupinatum) sobre caruru (Amaranthus retroflexus), campainha (Convolvulus arvensis), centeio (Secale cereale), mostarda-doscampos (Sinapis arvensis) (MAIGHANY et al., 2007) e girassol (Helianthus annuus) sobre picãopreto (CORSATO et al., 2010) e soja (BORTOLINI; FORTES, 2005; CORSATO et al., 2010).

Ocorreu interação entre os fatores estudados, para a variável percentagem de germinação de picão-preto (Tabela 2). Quando comparados os efeitos dos extratos da planta inteira das culturas de cobertura, ocorreu germinação de $11,1 \%$ e não ocorreu germinação $(0 \%)$ de aquênios de picão-preto quando em presença de extratos da planta inteira de canola, nas concentrações de 5 e $10 \%$ respectivamente. O extrato de trevovesiculoso em sua maior concentração também inibiu completamente a germinação da planta daninha em estudo, a semelhança ao ocorrido com a canola. Observou-se tanto para a canola quanto para o trevo-vesiculoso na maior concentração que houve inibição total da germinação, demonstrando que as duas culturas de coberturas constituem-se importantes ferramentas de controle de picão-preto. 
Figura 1. Efeito de extratos de partes vegetativas de plantas de cobertura de solo, no índice de velocidade de germinação de sementes de Bidens pilosa (picão-preto). ( $\circ$ planta inteira; $\bullet$ parte aérea; $\boldsymbol{\nabla}$ sistema radical). $\mathrm{R}^{2}$ : Coeficiente de determinação; ${ }^{\text {ns }} \mathrm{e}$ * não significativo e significativo, respectivamente $(\mathrm{p} \leq 0,05)$.

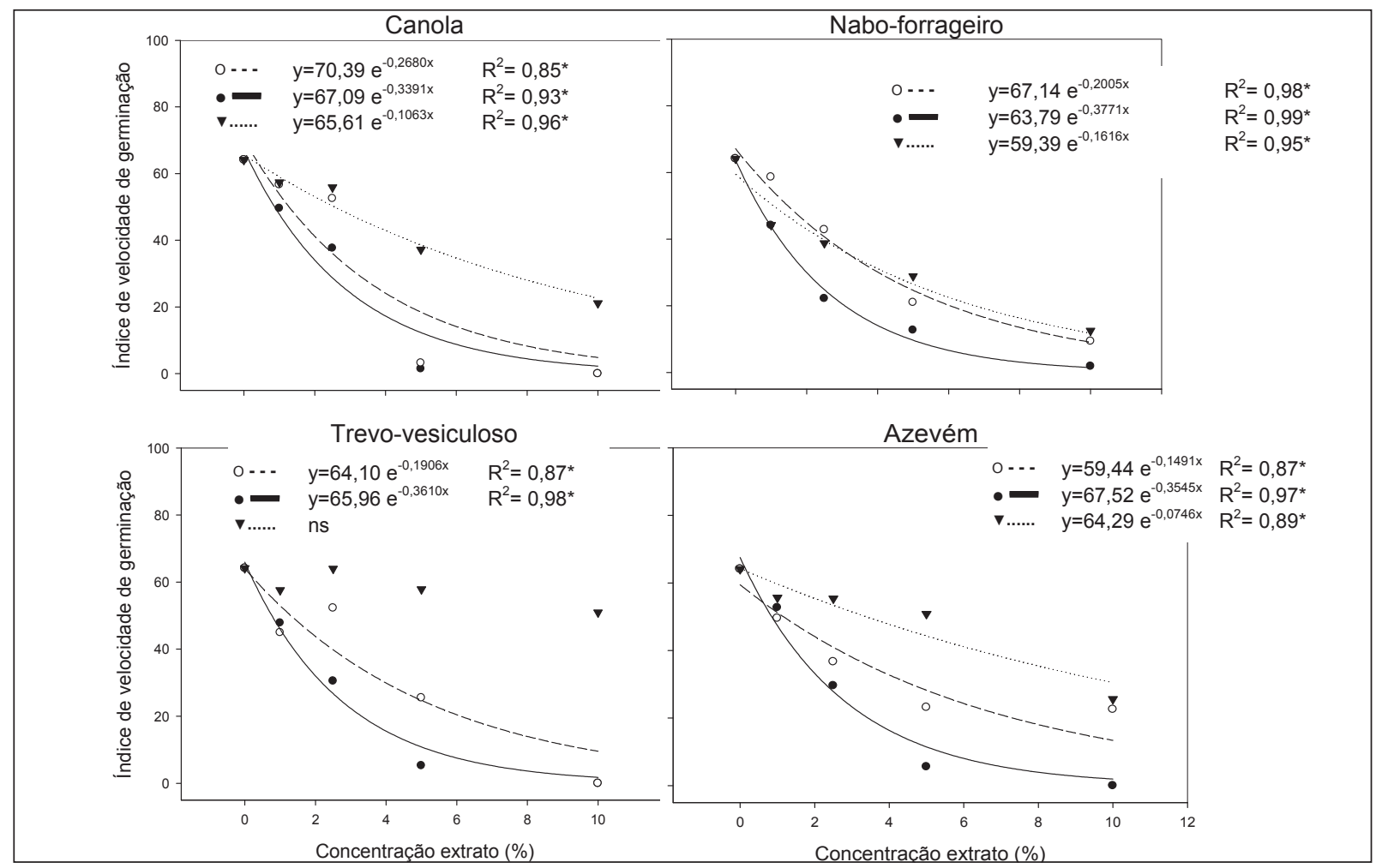

Fonte: Elaboração dos autores.

A percentagem de germinação de aquênios de picão-preto foi menor quando aplicado extratos da parte aérea de canola e trevo-vesiculoso, nas duas maiores concentrações, sendo que na maior concentração (10\%) a germinação dos aquênios foi totalmente inibida (Tabela 2). Resultados semelhantes foram observados na maior concentração para azevém. Estes resultados corroboram aos encontrados por Rizzardi et al. (2008) e Almeida (1991), onde extratos de canola apresentam potencial alelopático em reduzir a germinação de aquênios de picão-preto em até $80 \%$, conforme aumento da concentração dos extratos e por Liebman e Sundberg (2006), onde extratos da parte aérea de trevo-vermelho (Trifolium pratense), reduz a germinação e crescimento de diferentes plantas daninhas.

Os extratos do sistema radicular de plantas de cobertura, em geral, reduziram de forma pouco expressiva a germinação de picão-preto, sendo $11 \%$, na média de todas as concentrações, excluindo as testemunhas (Tabela 2). O potencial alelopático do sistema radicular tem baixa atividade, quando comparado a parte aérea (WANDSCHEER; PASTORINI, 2008), podendo em alguns casos ocorrer estímulo no desenvolvimento inicial de algumas espécies, L. multiflorum, Dactylis glomerata e Medicago sativa (EMETERIO; ARROYO; CANALS, 2004).Quando comparado o potencial alelopático das partes das plantas, 
para cada cultura, de modo geral, na média das concentrações dos extratos da planta inteira e parte aérea, excluindo as testemunhas, reduziram em 27 e 54\% a germinação, comparativamente ao sistema radicular (Tabela 2).

Os extratos do sistema radicular de plantas de cobertura, em geral, reduziram de forma pouco expressiva a germinação de picão-preto, sendo $11 \%$, na média de todas as concentrações, excluindo as testemunhas (Tabela 2). O potencial alelopático do sistema radicular tem baixa atividade, quando comparado a parte aérea (WANDSCHEER; PASTORINI, 2008), podendo em alguns casos ocorrer estímulo no desenvolvimento inicial de algumas espécies, L. multiflorum, Dactylis glomerata e Medicago sativa (EMETERIO; ARROYO CANALS, 2004).Quando comparado o potencial alelopático das partes das plantas, para cada cultura, de modo geral, na média das concentrações dos extratos da planta inteira e parte aérea, excluindo as testemunhas, reduziram em 27 e 54\% a germinação, comparativamente ao sistema radicular (Tabela 2 ).

A concentração dos extratos das partes das culturas de coberturas, para a variável resposta germinação de picão-preto, demonstrou ajuste dos dados ao modelo (Figura 2). Os extratos da parte aérea das culturas de cobertura apresentaram maior redução na germinação, comparativamente as demais partes vegetais. Observou-se que a parte aérea dos extratos de trevo-vesiculoso foi o que apresentou maior redução na germinação, embora os dados não tenham se ajustado ao modelo para todas as partes das plantas. Semelhantemente, Ohno et al. (2000), verificaram que a inibição do crescimento de mostarda (Brassica kaber), pelo extrato aquoso da parte aérea de trevo-vermelho foi linearmente proporcional a concentração do extrato aplicado.

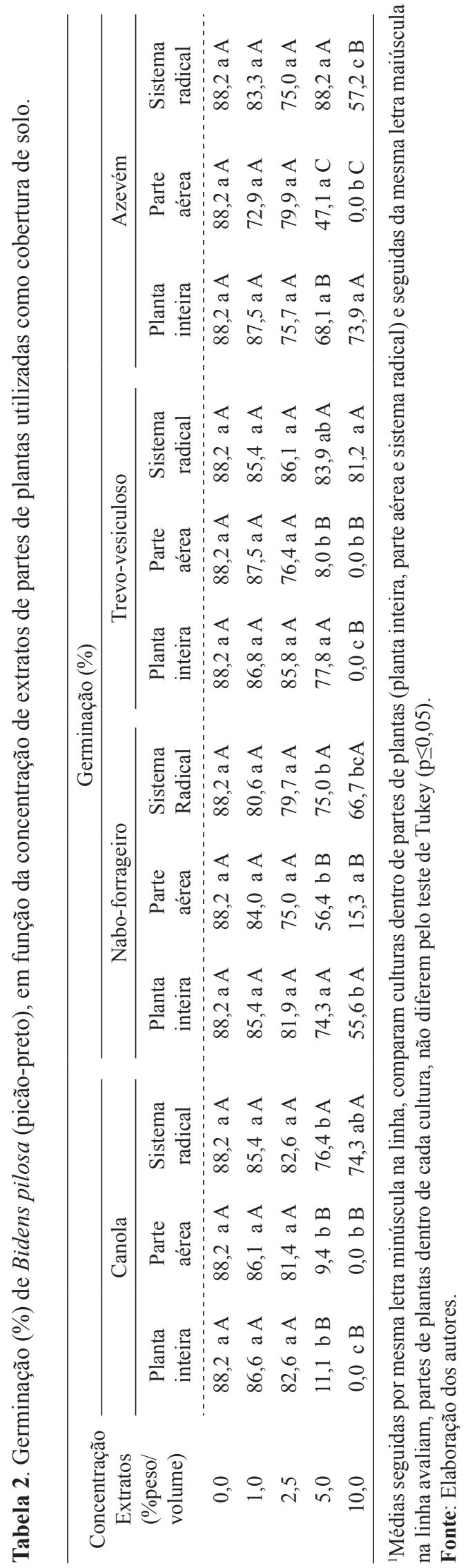


Figura 2. Efeito de extratos de partes vegetativas de plantas de cobertura de solo, na germinação (\%) de Bidens pilosa (picão-preto). ( $\circ$ planta inteira; • parte aérea; $\boldsymbol{\nabla}$ sistema radical). $\mathrm{R}^{2}$ : Coeficiente de determinação; ${ }^{\text {ns }} \mathrm{e}{ }^{*}$ não significativo e significativo, respectivamente $(\mathrm{p} \leq 0,05)$.

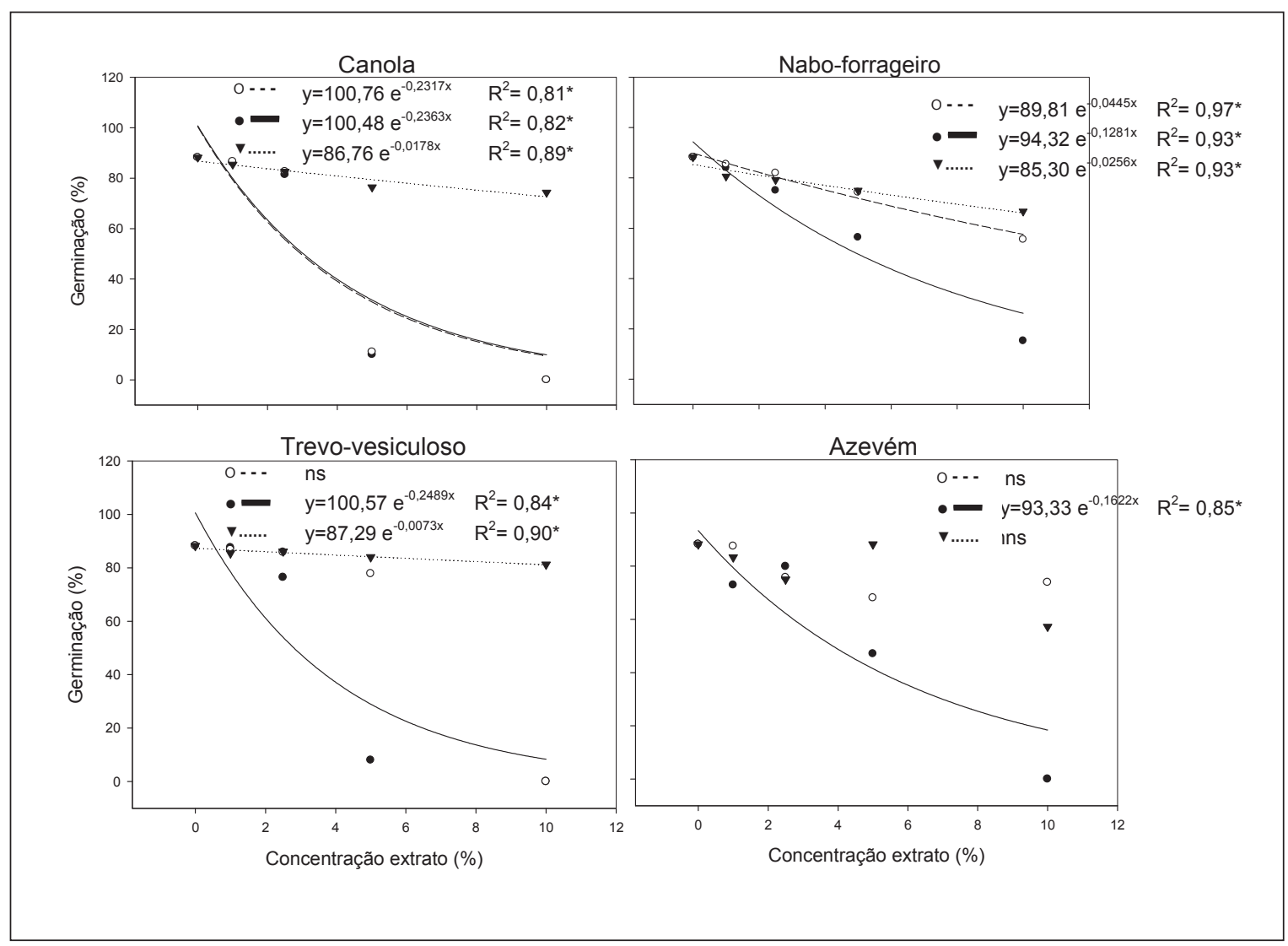

Fonte: Elaboração dos autores.

Para a variável comprimento da parte aérea (CPA) de plântulas de picão-preto, verificou-se interação entre os fatores (Tabela 3). Os extratos da planta inteira de canola reduziram o CPA em $100 \%$ nas duas maiores concentrações, enquanto que trevo-vesiculoso nas mesmas concentrações reduziram em $75 \%$ a variável, comparativamente a testemunha. Segundo Tawaha e Turk (2003), a aplicação de extratos da planta inteira de mostarda-preta sobre sementes de cevada selvagem (Hordeum spontaneum), proporcionou redução no CPA, comparado a extratos de raizes. Também, extratos de canola aplicados sobre sementes de capim-marmelada e capim-carrapicho (Cenchrus echinatus), promoveram redução do CPA (ALMEIDA, 1991).
O CPA de plântulas de picão-preto foi afetado pelos extratos da parte aérea das culturas. Dentre as culturas aparentemente o trevo-vesiculoso proporcionou maior redução do CPA das plântulas, em todas as concentrações dos extratos, enquanto as demais culturas igualaram-se somente na maior concentração (Tabela 3). Estudos com trevopersa e trevo-alexandrino (Trifolium alexandrium) demonstraram que extratos aquosos inibem o comprimento da parte aérea de campainha, mostardados-campos e caruru nas maiores concentrações devido a presença de compostos fenólicos que são solúveis em água e podem apresentar fitotoxicidade (MAIGHANY et al., 2007), fato também constatado nesse trabalho. 
Os extratos do sistema radicular de todas as espécies testadas apresentaram baixa influência na redução do CPA das plântulas de picão-preto, provavelmente por terem sido lavados perdendo suas propriedades alelopáticas, conforme discutido anteriormente (Tabela 3).

A maior redução do CPA das plântulas de picão-preto, para todas as culturas e em todas as concentrações testadas, em geral, foi verificado para parte aérea, em comparação aos extratos da planta inteira e do sistema radical (Tabela 3). Entretanto, houve exceção para os extratos da planta inteira de canola que reduziram em média, em relação à testemunha, $56 \%$ do CPA de picão-preto, comparado aos 48 e $17 \%$ de redução ocasionada pelos extratos da parte aérea e sistema radical, respectivamente.

Diferenças nas respostas alelopáticas de compostos de diferentes órgãos de uma mesma planta foram registrados com losna-brava (Artemisia absinthium) (DELACHIAVE; RODRIGUES, ONO, 1999) e trigo (Triticum aestivium) (WU et al., 2000). Segundo Javaid et al. (2006), extratos da parte aérea de sorgo tem maior potencial alelopático do que extratos do sistema radical, provavelemte pela presença de sorgoleone.

Para a variável resposta CPA de picão-preto, somente houve ajuste dos dados ao modelo para planta inteira e parte aérea das culturas de cobertura, com exceção de azevém em que somente houve ajuste para parte aérea (Figura 3). Para todas as culturas de cobertura, os extratos da parte aérea, comparativamente a extratos da planta inteira, foram mais eficientes na redução do CPA de picãopreto, com exceção dos extratos da canola. Quando comparados aos extratos da parte aérea, a cobertura de trevo-vesiculoso apresentou maior efeito alelopático na redução do CPA, conforme o parâmetro $b$ do modelo. Concentrações baixas de extratos da parte aérea de leucena (Leucaena spp.) não afetam o CPA de pega-pega (Desmodium sp.), caruru e picão-preto, mas em concentrações mais altas, interferem no comprimento (PIRES et al., 2001).

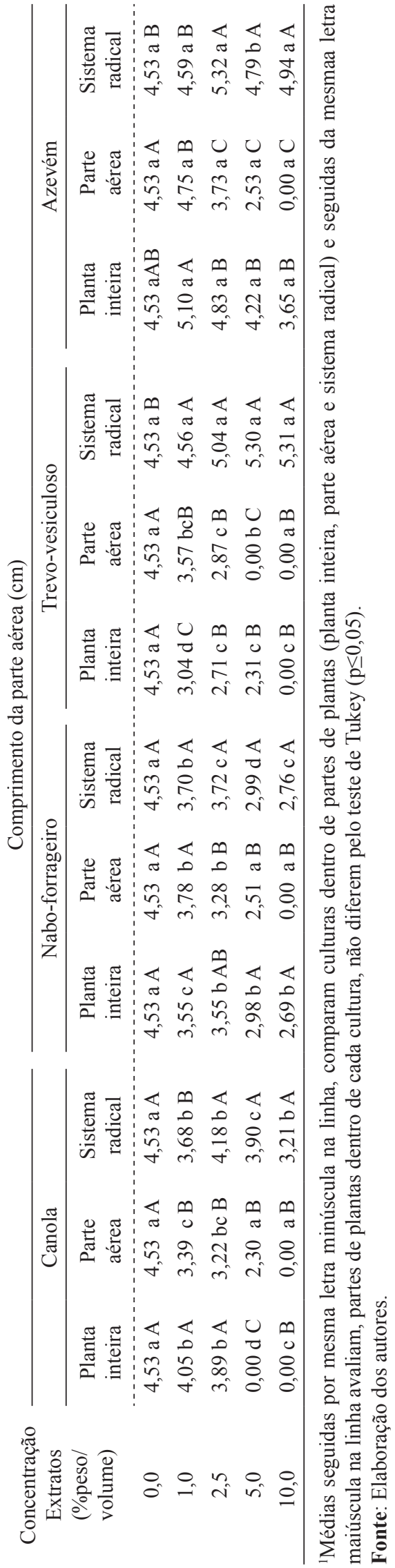


Para extratos da planta inteira, a cultura da canola apresentou efeitos severos na inibição do CPA das plântulas de picão-preto. Já os extratos de planta inteira de nabo-forrageiro e trevo-vesiculoso não demonstraram interferências tão marcantes, conforme o parâmetro $b$ do modelo (Figura 3).

Figura 3. Efeito de extratos de partes vegetativas de plantas de cobertura de solo, no comprimento da parte aérea $(\mathrm{cm})$ de plântulas de Bidens pilosa (picão-preto). ( $\mathrm{planta} \mathrm{inteira;} \bullet$ parte aérea; $\mathbf{\nabla}$ sistema radical). $\mathrm{R}^{2}$ : Coeficiente de determinação; ${ }^{\text {ns }} \mathrm{e} *$ não significativo e significativo, respectivamente $(\mathrm{p} \leq 0,05)$.

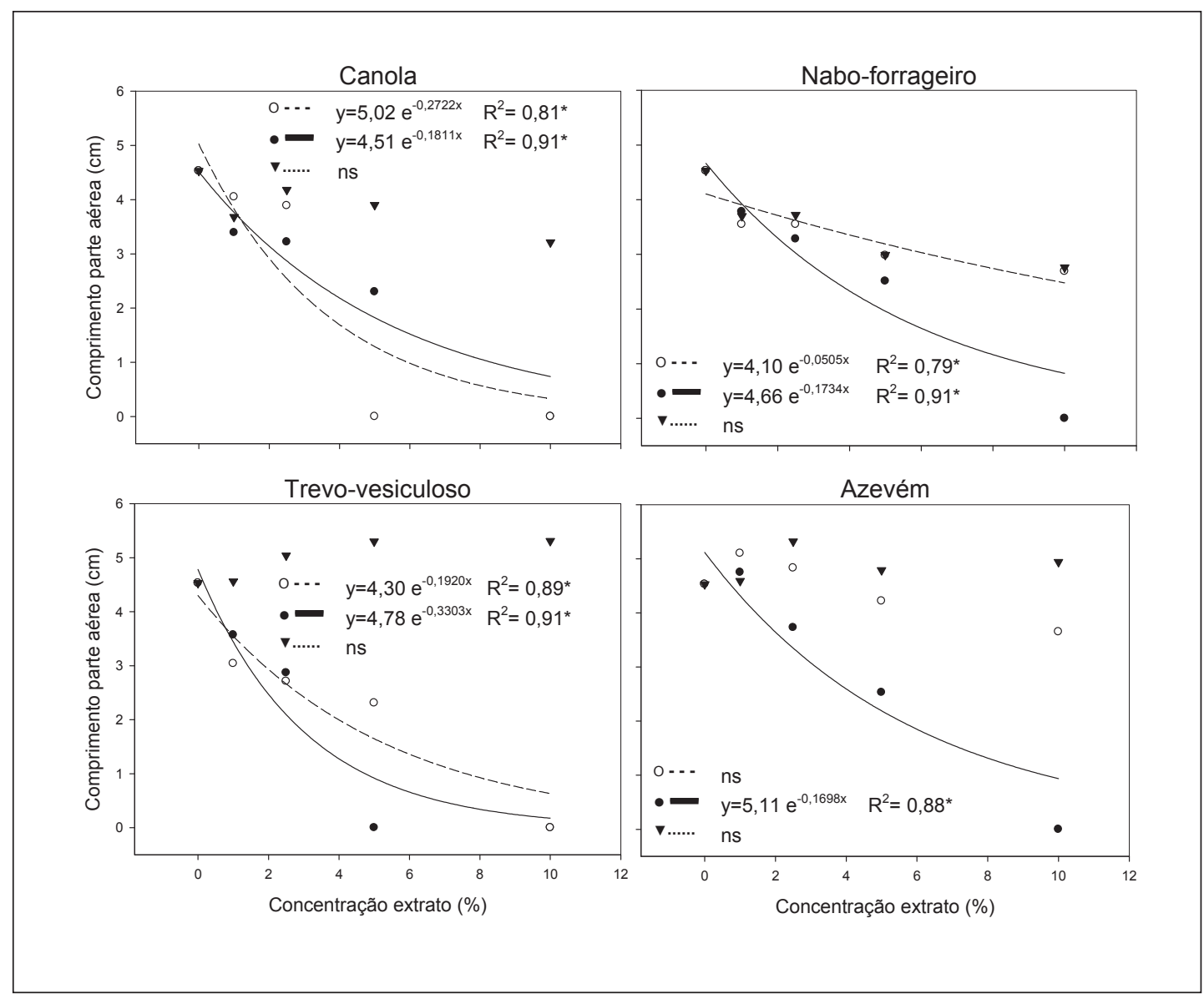

Fonte: Elaboração dos autores.

Houve interações entre os fatores testados para a variável comprimento radicular (CR) de plântulas de picão-preto (Tabela 4). Quando comparados os extratos da planta inteira das culturas de cobertura, os extratos de canola e trevo-vesiculoso apresentaram maior redução do CR nas duas maiores concentrações dos extratos, superando os extratos da planta inteira das demais culturas de cobertura de solo (Tabela 4). Estes resultados corroboram aos de Zamorano e Fuentes (2005), em que extratos de mostarda (Brassica campestris) reduziram o comprimento radicular de plântulas de tomate, nas maiores concentrações. Em estudo com extratos de conola, verificou-se redução do desenvolvimento de radículas de plântulas de capim-marmelada e capim-carrapicho (ALMEIDA, 1991). 


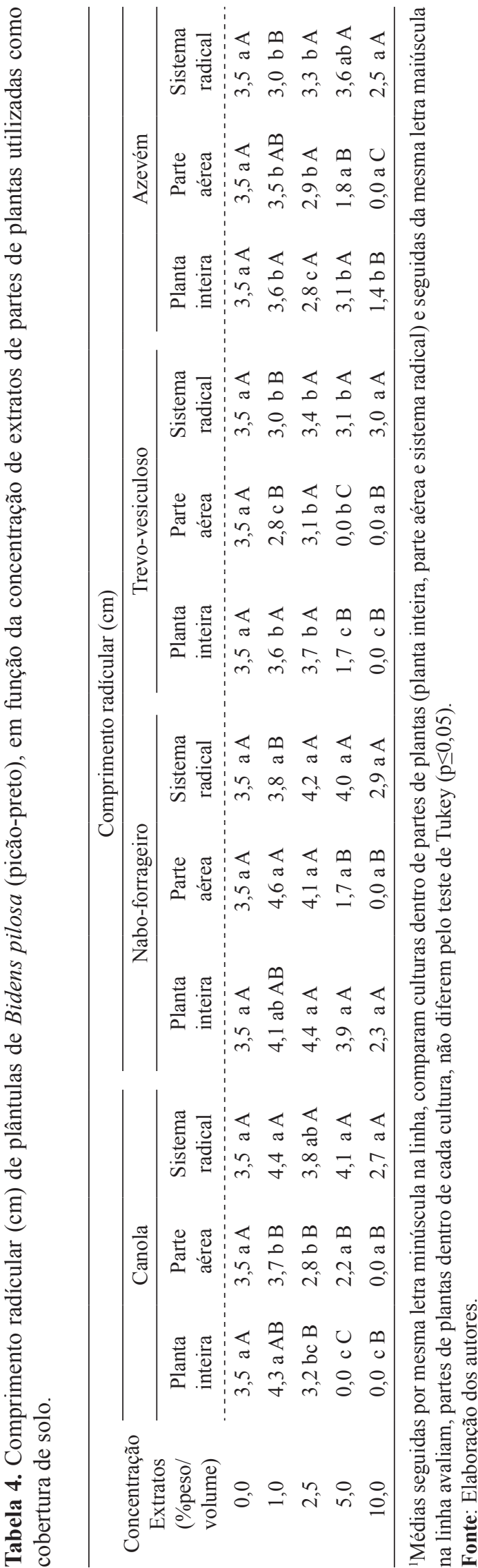

Os extratos da parte aérea das culturas de cobertura demonstram que o trevo-vesiculoso reduziu o CR de plântulas de picão-preto, em todas as concentrações dos extratos, com redução de 100\% nas duas maiores concentrações (Tabela 4). As demais culturas na maior concentração reduziram a 100\% o $\mathrm{CR}$ de picão-preto. Estes resultados estão de acordo com os apresentados por Liebman e Sundberg (2006), os quais verificaram que os compostos fenólicos presentes nos extratos de trevo-vermelho, além de reduzir o comprimento da parte aérea, também pode reduzir o comprimento radicular de plântulas magnoliopsidas de forma mais eficiente que do em liliopsidas.

Quando comparados os extratos do sistema radical, verificou-se pouca influência na redução do CR das plântulas, sendo que trevo-vesiculoso e azevém proporcionaram maior redução. Já os extratos de canola e nabo-forrageiro apresentaram efeitos brandos (Tabela 4).

A comparação das partes vegetativas de cada cultura, em geral, demonstrou que a parte aérea das culturas apresentou maior redução do $\mathrm{CR}$, com exceção da planta inteira de canola, que apresentou maior efeito alelopático do que a parte aérea (Tabela 4).

A concentração dos extratos das partes das culturas de coberturas, para a variável resposta $\mathrm{CR}$ de plântulas de picão-preto, apresentou ajuste dos dados ao modelo para extratos da planta inteira de trevo-vesiculoso e azevém, e parte aérea de todas as culturas de cobertura, com exceção de naboforrageiro que não demonstrou ajuste ao modelo para nenhuma das partes vegetais (Figura 4). Os extratos da parte aérea de trevo-vesiculoso e azevém apresentaram maior redução no $\mathrm{CR}$ de picão-preto, do que extratos da planta inteira, como pode ser visto pelo menor valor do parâmetro b do modelo. Esta redução no CR das plântulas de picão-preto, pelos extratos de trevo-vesiculoso deve-se principalmente a redução da taxa de divisão e elongação celular (MAIGHANY et al., 2007) e/ou pela presença de compostos fenólicos (OHNO; DOOLAN, 2001). 
Figura 4. Efeito de extratos de partes vegetativas de plantas de cobertura de solo, no crescimento radicular (cm) de plântulas de Bidens pilosa (picão-preto). ( $\circ$ planta inteira; • parte aérea; $\boldsymbol{\nabla}$ sistema radical). $\mathrm{R}^{2}$ : Coeficiente de determinação; ${ }^{\text {ns }} \mathrm{e} *$ não significativo e significativo, respectivamente $(\mathrm{p} \leq 0,05)$.
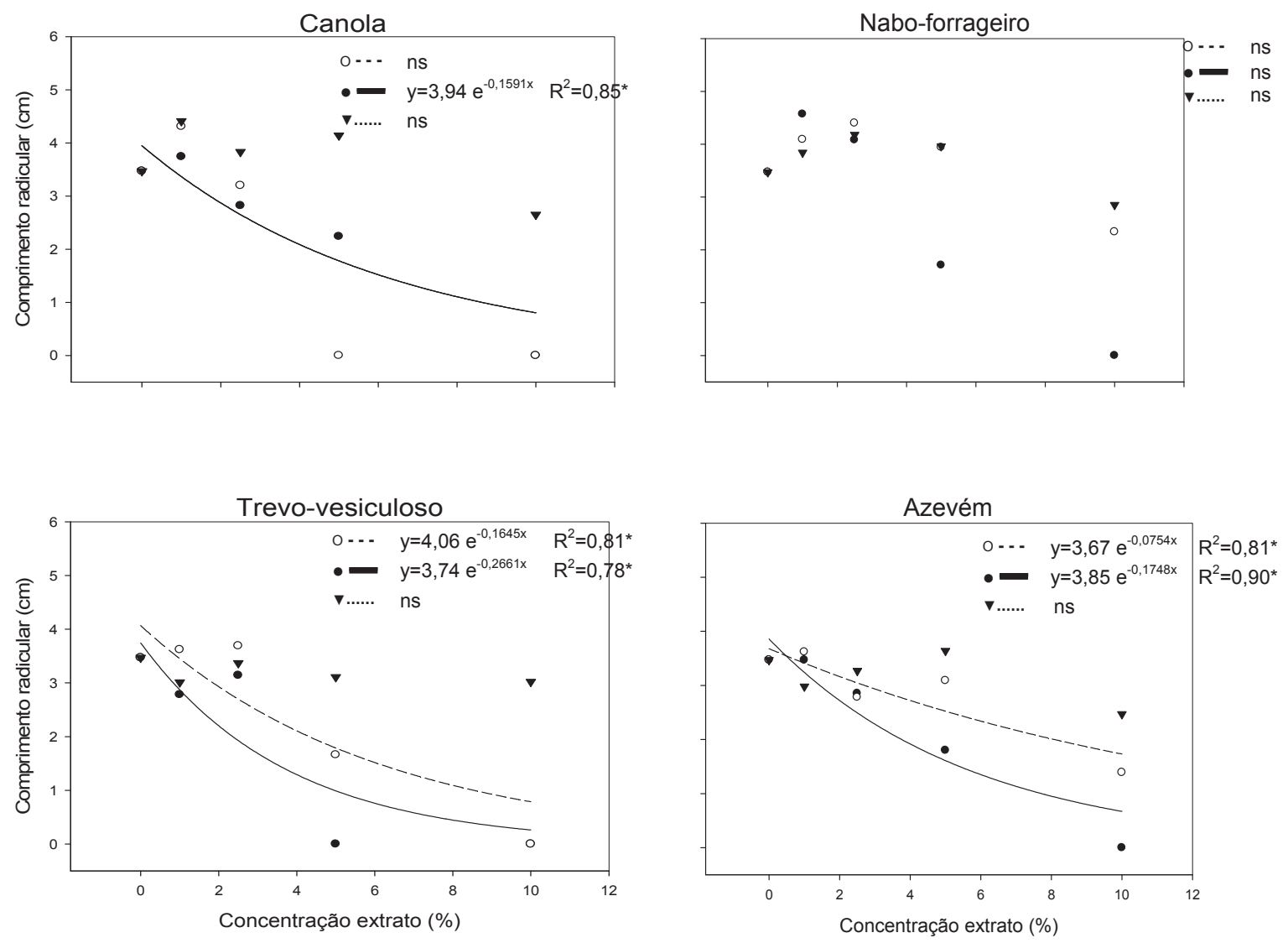

Fonte: Elaboração dos autores.

A redução no CR das plântulas de picão-preto foi dependente da concentração dos extratos. Trabalhos relatam que o comprimento radical de plântulas apresentam relação direta com a concentração do extrato, ou seja, quanto maior a concentração do extrato maior é a inibição das raízes das plântulas (RIZZARDI et al., 2008; MAULI et al., 2009; CORSATO et al., 2010). Assim, o comprimento radical pode ser um bom parâmetro para registro de atividade alelopática, visto que este órgão é mais sensível do que a parte aérea (PIRES et al., 2001).

Os fatores testados apresentaram interação para a variável MSPA de plântulas de picão-preto (Tabela 5). Quando comparados os extratos da planta inteira das culturas de cobertura, a redução na MSPA foi maior ao se aplicar extratos de planta inteira de canola, nas duas maiores concentrações. Os extratos da planta inteira de trevo-vesiculoso não afetaram a MSPA, até mesmo nas maiores concentrações dos extratos, demonstrando baixa capacidade alelopática em inibir a MSPA da planta daninha. Extratos da planta inteira de mostarda-preta reduziram a MSPA de cevada selvagem em todas as concentrações estudadas (TAWAHA; TURK, 2003), provavelmente pela presença de glicosinolatos (RIZZARDI et al., 2008). Norsworthy (2003) relata que, resíduos de brassicas no solo também podem afetar a germinação, reduzir o estabelecimento e crescimento de plantas daninhas. 


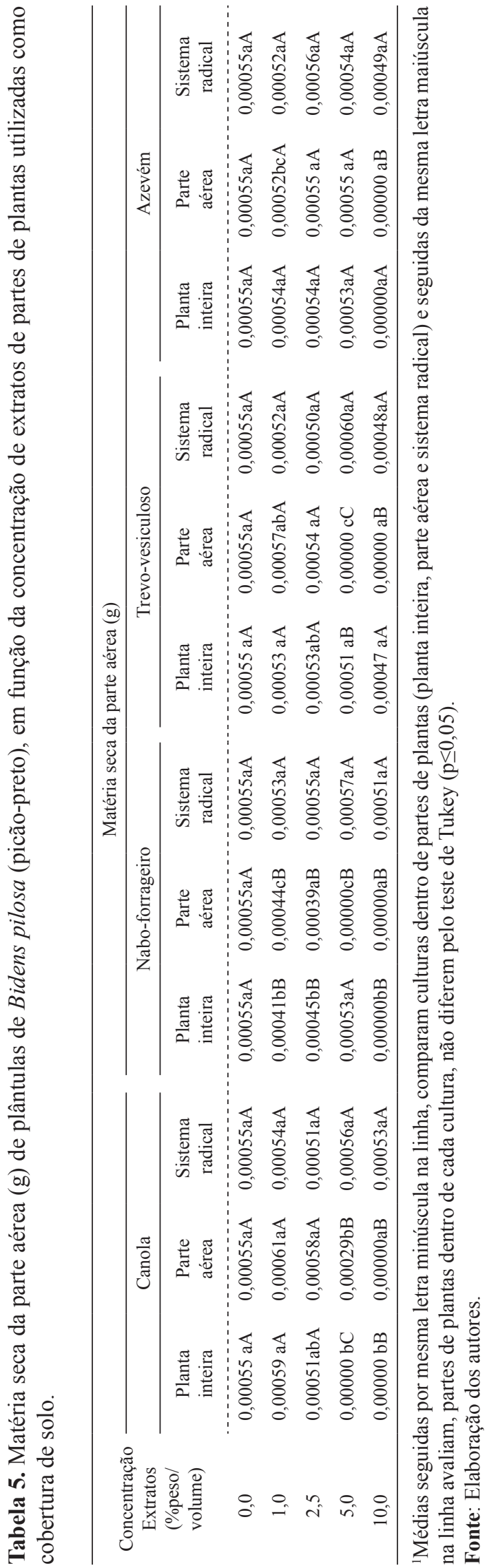

Extratos da parte aérea de nabo-forrageiro e trevo-vesiculoso apresentaram atividade alelopática mais acentuada nas duas maiores concentrações, reduzindo a MSPA de plântulas de picão-preto (Tabela 5). Por sua vez, os extratos do sistema radical das plantas de cobertura não influenciaram a MSPA das plântulas de picão-preto.

Quando comparada as partes vegetativas de cada cultura de cobertura, verificou-se que a planta inteira de canola apresentou maior efeito alelopático do que a parte aérea e sistema radical no acúmulo de MSPA de plântulas de picão-preto (Tabela 5). Para as demais culturas de cobertura, os extratos da parte aérea nas maiores concentrações apresentaram efeito mais acentuado reduzindo a MSPA, quando comparado a extratos da planta inteira e sistema radical.

Para os extratos de azevém, não houve ajuste de dados ao modelo, para as demais culturas houve ajuste dos dados aos extratos da planta inteira de canola e parte aérea de canola, nabo-forrageiro e trevo-vesiculoso (Figura 5). Extratos da planta inteira de canola apresentaram maior efeito alelopático do que a parte aérea, como demonstra o parâmetro b do modelo. Quando comparando os extratos da parte aérea, o nabo-forrageiro apresentou maior efeito alelopático, reduzindo o acúmulo de MSPA de plântulas de picão-preto a partir de concentrações baixas de extratos (Figura 5).

Ocorreu interação entre os fatores estudados, para a variável matéria seca radicular (MSR) de plântulas de picão-preto (Tabela 6). Na comparação dos extratos da planta inteira das culturas de cobertura, os extratos de canola nas duas maiores concentrações reduziram em 100\% a MSR. Os extratos de nabo-forrageiro e canola apresentaram redução da MSR de modo similar na maior concentração, o que não ocorreu com o e trevovesiculoso e o azevém (Tabela 6).

Quando comparados os extratos da parte aérea das culturas de cobertura, observou-se que extratos de nabo-forrageiro e trevo-vesiculoso, nas duas 
maiores concentrações reduziram em 100\% o acúmulo da MSR, porém na maior concentração as demais culturas apresentaram reduções similares na redução da MSR de picão-preto (Tabela 6). Já, as concentrações dos extratos do sistema radical das culturas de cobertura, apresentaram diferença na inibição da MSR de plântulas de picão-preto, porém reduzindo de forma menos expressiva a variável avaliada. Pela média dos extratos, o azevém apresentou maior tendência na redução da
MSR de picão-preto, reduzindo em 32\% a variável, comparativamente as demais espécies testadas.

A comparação entre as partes vegetais de cada espécie utilizada como cobertura de solo, na média de todas as concentrações dos extratos, demonstrou, de modo geral, que os extratos da parte aérea de todas as culturas de cobertura apresentaram maior redução na MSR das plântulas de picão-preto (Tabela 6), a exceção de canola, em que os extratos da planta inteira proporcionaram maior redução do que as demais partes vegetais.

Figura 5. Efeito de extratos de partes vegetativas de plantas de cobertura de solo, na matéria seca da parte aérea $(\mathrm{g})$ de plântulas de Bidens pilosa (picão-preto). ( $\mathrm{planta} \mathrm{inteira;} \bullet$ parte aérea; $\boldsymbol{\nabla}$ sistema radical). $\mathrm{R}^{2}$ : Coeficiente de determinação; ${ }^{\text {ns }} \mathrm{e}^{*}$ não significativo e significativo, respectivamente $(\mathrm{p} \leq 0,05)$.

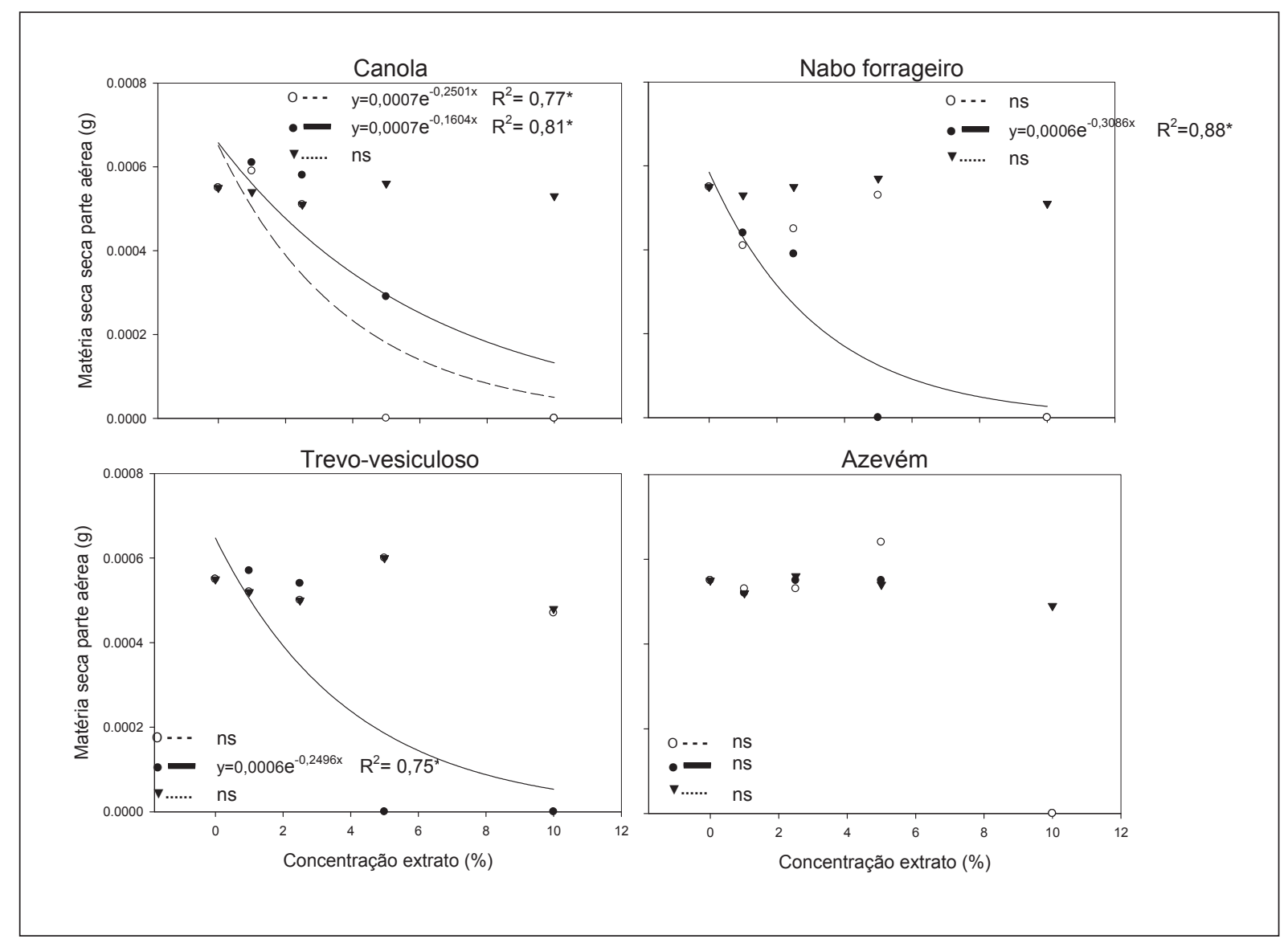

Fonte: Elaboração dos autores. 
O fator concentração dos extratos, para a variável resposta MSR, demonstrou ajuste dos dados ao modelo, para os extratos da planta inteira de canola e trevo-vesiculoso, da parte aérea das quatro culturas e do sistema radical de trevo-vesiculoso (Figura 6). Quando comparados os extratos das partes vegetais de cada cultura de cobertura, pode-se observar que a parte aérea apresentou maior potencial alelopático sobre picão-preto, com exceção de extratos da planta inteira de canola, como demonstra o parâmetro $b$ do modelo. Na comparação dentro de parte vegetais, pode-se observar que extratos da planta inteira de canola e extratos da parte aérea de nabo-forrageiro apresentaram maior redução no acúmulo de MSR das plântulas de picão-preto de forma eficaz (Figura 6).

Osextratosdecanola,emgeral,apresentarammaior potencial alelopático, seguido de trevo-vesiculoso, afetando a germinação e o desenvolvimento de picão-preto. A parte aérea das culturas de cobertura foi a que apresentou, em geral, maior atividade alelopática, sobre a germinação e o desenvolvimento de picão-preto. A atividade alelopática é maior com o incremento da concentração dos extratos, das diferentes partes vegetais destacando-se o IVG como melhor indicador da atividade alelopática de canola, nabo-forrageiro, trevo-vesiculoso e azevém sobre picão-preto.

Figura 6. Efeito de extratos de partes vegetativas de plantas de cobertura de solo, na matéria seca radicular (g) de plântulas de Bidens pilosa (picão-preto). ( $\circ$ planta inteira; $\bullet$ parte aérea; $\boldsymbol{\nabla}$ sistema radical). $\mathrm{R}^{2}$ : Coeficiente de determinação; ${ }^{\text {ns }} \mathrm{e} *$ não significativo e significativo, respectivamente $(\mathrm{p} \leq 0,05)$.

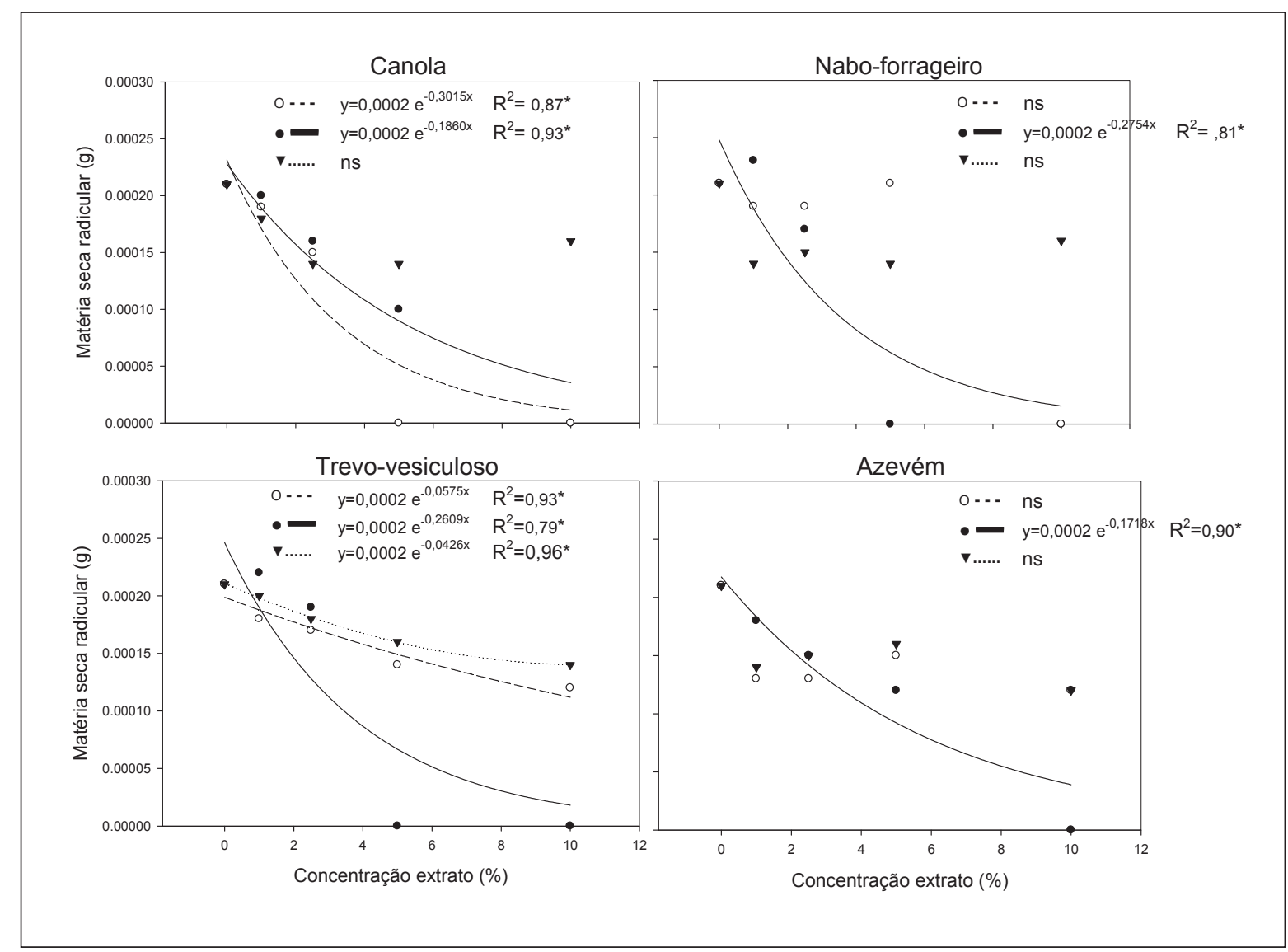

Fonte: Elaboração dos autores. 


\section{Referências}

ALMEIDA, F. S. Controle de plantas daninhas no plantio direto. Londrina: IAPAR, 1991. 34 p. (IAPAR, Circular 67).

BORTOLINI, M. F.; FORTES, A. M. T. Efeitos alelopáticos sobre a germinação de sementes de soja (Glycine max). Semina: Ciências Agrárias, Londrina, v. 26, n. 1, p. 5-10, 2005.

CARMONA, R.; BÔAS, H. D. C. V. Dinâmica de sementes de Bidens pilosa no solo. Pesquisa Agropecuária Brasileira, Brasília, v. 36, n. 3, p. 457-463, 2001.

CORSATO, J. M.; FORTES, A. M. T.; SANTORUM, M.; LESZCZUNSKI, R. Efeito alelopático do extrato aquoso de folhas de girassol sobre a germinação de soja e picao-preto. Semina: Ciências Agrárias, Londrina, v. 31, n. 2, p. 353-360, 2010.

DELACHIAVE, M. E. A.; RODRIGUES, J. D.; ONO, E. O. Efeitos alelopáticos de losna (Artemisia absinthium L.) na germinação de sementes de pepino, milho, feijão e tomate. Revista Brasileira de Sementes, Brasília, v. 21, n. 2, p. 265-269, 1999.

EMETERIO, L. S.; ARROYO, A.; CANALS, R. M. Allelopathic potential of Lolium rigidum Gaud. on the early growth of three associated pasture species. Grass and Forage Science, Singapore, v. 59, n. 2, p. 107-112, 2004.

JAVAID, A.; SHAFIQUE, S.; BAJWA, R.; SHAFIQUE, S. Effect of aqueous extracts of allelopathic crops on germination and growth of Parthenium hysterophorus $\mathrm{L}$. South African Journal of Botany, South Africa, v. 72, n. 4, p. 609-612, 2006.

KHANH, T. D.; CHUNG, M. I.; XUAN, T. D.; TAWATA, $\mathrm{S}$. The exploitation of crop allelopathy in sustainable agricultural production. Journal Agronomy \& Crop Science, Minnesota, v. 191, n. 3, p. 172-184, 2005.

LIEBMAN, M.; SUNDBERG, D. N. Seed mass affects the susceptibility of weed and crop species to phytotoxins extratcted from red clover shoots. Weed Science, Champaign, v. 54, n. 2, p. 340-345, 2006.

MAIGHANY, F.; KHALGHANI, J.; MOHAMMAD, A. B.; NAJAFPOUR, M. Allelopathic potential of Trifolium resupinatum L. (Persian clover) and Trifolium alexandrium L. (Berseem clover). Weed Biology and Management, Okayama, v. 7, n. 3, p. 178-183, 2007.

MAULI, M. M.; FORTES, A. M. T.; ROSA, D. M.; PICCOLO, G.; MARQUES, D. S.; CORSATO, J. M.; LESZCYNSKY, R. Alelopatia de leucenasobre soja e plantas daninhas. Semina: Ciências Agrárias, Londrina, v. 30, n. 1, p. 55-62, 2009. 
NORSWORTHY, J. K. Allelopathic potencial of wild radish (Raphanus raphanistrum). Weed Technology, Lawrence, v. 17, n. 2, p. 307-313, 2003.

OHNO, T.; DOOLAN, K. L. Effects of red clover decomposition on phytotoxicity to wild mustard seedling growth. Applied Soil Ecology, Amsterdam, v. 16, n. 2, p. 187-1972, 2001.

OHNO, T.; DOOLAN, K. L.; ZIBILSKE, L. M.; LIEBMAN, M.; GALLANDT, E. R.; BERUBE, C. Phytotoxic effects of red clover amended soils on wild mustard seedling growth. Agriculture, Ecosystems \& Environment, Zürich, v. 78, n. 2, p. 187-192, 2000.

OLIVEIRA, T. K.; CARVALHO, G. J.; MORAES, R. N. S. Plantas de cobertura e seus efeitos sobre o feijoeiro em plantio direto. Pesquisa Agropecuária Brasileira, Brasília, v. 37, n. 8, p. 1079-1087, 2002.

PIRES, N. M. de; SOUZA, I. R. P.; PRATES, H. T.; FARIA, T. C. L. de; PEREIRA FILHO, I. A.; MAGALHÃES, P. C. Efeito do extrato aquoso de leucena sobre o desenvolvimento, índice mitótico e atividade da peroxidase em plântulas de milho. Revista Brasileira de Fisiologia Vegetal, Brasília, v. 13, n. 1, p. 55-65, 2001.

REZENDE, C. P.; PINTO, J. C.; EVANGELISTA, A. R.; SANTOS, I. P. A. dos. Alelopatia e suas interações na formação e manejo de pastagens. Lavras: Universidade Federal de Lavras, p. 1-55, 2003. (Boletim agropecuário, n. 54).

RIZZARDI, A.; RIZZARDI, M. A.; LAMB, T. D.; JOHANN, L. B. Potential alelopático de extratos aquosos de genótipos de canola sobre Bidens pilosa. Planta Daninha, Viçosa, MG, v. 26, n. 4, p. 117-724, 2008.

SANTOS, J. B.; CURY, J. P. Picão-preto: uma planta daninha especial em solos tropicais. Planta Daninha, Viçosa, MG, v. 29, p. 1159-1171, 2011. Especial.
SEVERINO, F. J.; CHRISTOFOLETI, P. J. Efeitos de quantidades de fitomassa de adubos verdes na supressão de plantas daninhas. Planta Daninha, Viçosa, MG, v. 19, n. 2, p. 223-228, 2001.

TAWAHA, A. M.; TURK, M. A. Allelopathic effects of black mustard (Brassica nigra) on germination and growth of wild barley (Hordeum spontaneum). Journal Agronomy \& Crop Science, Minnesota, v. 189, n. 5, p. 298-303, 2003.

VYVYAN, J. R. Allelochemicals as leads for new herbicides and agrochemicals. Thetrahedron, London, v. 58, n. 9, p. 1631-1646, 2002.

WANDSCHEER, A. C. D.; PASTORINI, L. H. Interferência alelopática de Raphanus raphanistrum L. sobre a germinação de Lactuca sativa L. e Solanum lycopersicon L. Ciência Rural, Santa Maria, v. 38, n. 4, p. 949-953, 2008.

WARDLE, A. D.; AHMED, M.; NICHOLSON, K. S. Allelopathic influence of nodding thistle (Carduns nutans L.) seed on germination and radicle growth of pasture plants. New Zeland Journal Agriculture Research, Sydney, v. 34, n. 2, p. 185-191, 1991.

WU, H.; HAIG, T.; PRATLEY, J.; LEMERLE, D.; AN, M. Distribution and exudation of allelochemicals in wheat Triticum aestivum. Journal of Chemical Ecology, Tampa, v. 26, n. 9, p. 2141-2154, 2000.

ZAMORANO, C.; FUENTES, C. L. Potencial alelopático de Brassica campestris subsp. Rapa y Lolium temulentum sobre la germinación de semillas de tomate. Agronomia Colombiana, Bogotá, v. 23, n. 2, p. 256-260, 2005. 